MATEC Web of Conferences 3, 01053 (2013)

DOI: $10.1051 /$ matecconf/20130301053

(C) Owned by the authors, published by EDP Sciences, 2013

\title{
Extraction of polyphenols
}

\author{
L. Loucif Seiad ${ }^{1}$, and R. Derriche ${ }^{2}$ \\ ${ }^{1}$ Department of Chemistry, Faculty of Sciences, UMBB, Boumerdes 35000, Algeria \\ ${ }^{2}$ Department of chemical engineering, Ecole Nationale Polytechnique, El Harrach, Algiers, Algeria
}

\begin{abstract}
The aim of the study is to investigate the influence of certain parameters on efficiency of the extraction of polyphenols from an Algerian tree (Pinus Halepensis Mill). Extraction was conducted in a stirred closed extractor. Our study was conducted to optimize the extraction conditions for total phenolic contents (TPC) using Folin Ciocalteu method. A response surface methodology (RSM) was launched to investigate the influence of process variables on extraction followed by a composite design (CD) approach. The statistical analysis revealed that the optimized conditions were for a temperature of $45^{\circ} \mathrm{C}$ and for the smallest particles.
\end{abstract}

\section{Introduction}

Polyphenol compounds have drawn the attention of researchers in recent years. These compounds are synthesized exclusively by plants; they are involved in defense against ultraviolet radiation or aggression by pathogens. Polyphenol are present in fruits, flowers, leafs, roots, and woody parts of plants, whereas external tissues include bigger amounts of these components [1, 2]. About 8000 plant polyphenol compounds have been identified, but their extraction is difficult for two main reasons: first, these compounds are extremely different in relation to their structure - they may occur in plant tissues combined with sugars, proteins or they may create polymerized derivatives of various insolubilities. Their chemical structure and interactions with other food components are not fully known and it is very important information at the selection of a solvent and terms and conditions of extraction. Second, polyphenols are susceptible to oxidation; furthermore high temperature and alkaline environment cause their degradation [3]. In this study, extraction of Polyphenols from Alep pine bark (Pinus Halepensis Mill) was achieved.

\section{Experimental}

\subsection{Plant material}

The studied sample comes from Alep pine bark (Pinus Halepensis Mill). They were collected locally from the north east of Algeria. The bark is crushed and the solid particles are sieved in order to prepare different samples. A binocular magnifying glass and high precision gauge were used in order to characterise the dimensions of the particles. The density of the bark was measured (1.79 $\mathrm{g} / \mathrm{ml})$. These fragments were ground in a porcelain mortar to a powder and stored after. The moisture content was determined by using device DEAN STARCK (13.97\%).

\subsection{Extraction}

The batch solid-liquid extraction was carried out in a reactor of $500 \mathrm{ml}$ witch content the required amount of ground bark, then acetone/water (75/25) which was chosen after preliminary tests (the preliminary tests are in accordance with Julkunen-Tiito [4]) was added. The half of the reactor is pushed into the thermostat bath. After magnetic stirring, the desired amount of the solution is removed with a graduated syringe to a precise time (depending on operating conditions). The TPC of samples was determined with Folin-Ciocalteu's phenol reagent [5].

\section{Modeling}

\subsection{Application of factorial design (FD)}

The design experiment is needed to evaluate the effects and interactions of three independent variables, namely temperature $\left({ }^{\circ} \mathrm{C}\right)\left(\mathrm{X}_{1}\right)$, mass $(\mathrm{g})\left(\mathrm{X}_{2}\right)$ and particle size $(\mathrm{mm})\left(\mathrm{X}_{3}\right)$. The coded levels and the natural values of the factors used in this experimental design are shown in Table 1 in parallel. The responses obtained for each experiment are also shown. The experimental designs used were constructed and the experimental results were processed by using the software STATGRAPHICS PLUS. An analysis of variance (ANOVA) with 95\% confidence level was then carried out for each response variable in order to test the model significance and suitability. The P-value in ANOVA defines the significance of the different variables. A description of significant effects obtained from ANOVA for TPC was described by a Standardized Pareto Chart. 
Table 1. Factorial design (FD).

\begin{tabular}{|c|c|c|c|c|c|c|c|c|}
\hline \multirow{2}{*}{$\begin{array}{c}\text { Exp } \\
\mathrm{N}\end{array}$} & \multicolumn{3}{|c|}{ Coded } & \multicolumn{3}{c|}{ Decoded variable } & \multicolumn{2}{c|}{ Response } \\
\cline { 2 - 9 } & $\mathrm{X}_{1}$ & $\mathrm{X}_{2}$ & $\mathrm{X}_{3}$ & $\mathrm{~T}^{*}$ & $\mathrm{M}_{\mathrm{v}}{ }^{*}$ & $\mathrm{D}^{*}$ & $\mathrm{Y}_{\text {exp }}$ & $\mathrm{Y}_{\text {calc }}$ \\
\hline 1 & -1 & -1 & -1 & 30 & 2.5 & 0.4 & 0.35 & 0.37 \\
\hline 2 & +1 & -1 & -1 & 60 & 2.5 & 0.4 & 0.43 & 0.45 \\
\hline 3 & -1 & +1 & -1 & 30 & 3.12 & 0.4 & 0.60 & 0.62 \\
\hline 4 & +1 & +1 & -1 & 60 & 3.12 & 0.4 & 0.58 & 0.60 \\
\hline 5 & -1 & -1 & +1 & 30 & 2.5 & 1.25 & 0.27 & 0.28 \\
\hline 6 & +1 & -1 & +1 & 60 & 2.5 & 1.25 & 0.20 & 0.21 \\
\hline 7 & -1 & +1 & +1 & 30 & 3.12 & 1.25 & 0.32 & 0.34 \\
\hline 8 & +1 & +1 & +1 & 60 & 3.12 & 1.25 & 0.33 & 0.35 \\
\hline 9 & 0 & 0 & 0 & 45 & 2.77 & 0.825 & 0.45 & 0.40 \\
\hline 10 & 0 & 0 & 0 & 45 & 2.77 & 0.825 & 0.44 & 0.40 \\
\hline 11 & 0 & 0 & 0 & 45 & 2.77 & 0.825 & 0.43 & 0.40 \\
\hline
\end{tabular}

* $\mathrm{T}=\mathrm{X}_{1}=$ Temperature $\left({ }^{\circ} \mathrm{C}\right) ; \mathrm{M}_{\mathrm{v}}=\mathrm{X}_{2}=$ vegetable matter $(\mathrm{g})$; $\mathrm{D}=\mathrm{X}_{3}=$ particle size $(\mathrm{mm}) ; \mathrm{Y}_{\exp }=$ experimental mass or extracted mass and $\mathrm{Y}_{\text {calc }}=$ calculated mass or theoretical mass.

As can be seen from table 1, the best result is obtained for a temperature of $30^{\circ} \mathrm{C}$ and for the smallest size (Exp $N^{\circ} 3$ ). The optimal conditions Coefficient de determination ajusté obtained from the first derivatives of the first-order polynomial equation resulted imaginary values or experimental field is real so they can't be solution to our system. The optimum is corresponding to Exp $\mathrm{N}^{\circ} 3$. The optimum is not precisely identified we will expand the field to study the model of second order.

\subsection{Application of composite design}

To get a good reproducibility of the experiments, the number of repetitions at the central point was six. The interval was extended to $(-\alpha,+\alpha)$. The value of $\alpha$ is 1,68 . We therefore extend our interval of study to elucidate the effect of the parameters studied and therefore can improve the model with the quadratic form Table 2.

Table 2. Composite rotastable design (CD).

\begin{tabular}{|c|c|c|c|c|c|}
\hline \multirow{2}{*}{ Ex N $^{\circ}$} & \multicolumn{3}{|c|}{ Coded variable } & \multicolumn{2}{c|}{ Response } \\
\cline { 2 - 6 } & $\mathrm{X}_{1}$ & $\mathrm{X}_{2}$ & $\mathrm{X}_{3}$ & $\mathrm{Y}_{\mathrm{ex}}$ & $\mathrm{Y}_{\text {calc }}$ \\
\hline 1 & -1 & -1 & -1 & 0.35 & 0.49 \\
\hline 2 & +1 & -1 & -1 & 0.43 & 0.53 \\
\hline 3 & -1 & +1 & -1 & 0.60 & 0.72 \\
\hline 4 & +1 & +1 & -1 & 0.58 & 0.76 \\
\hline 5 & -1 & -1 & +1 & 0.27 & 0.34 \\
\hline 6 & +1 & -1 & +1 & 0.20 & 0.22 \\
\hline 7 & -1 & +1 & +1 & 0.32 & 0.34 \\
\hline 8 & +1 & +1 & +1 & 0.33 & 0.31 \\
\hline 9 & 0 & 0 & 0 & 0.45 & 0.45 \\
\hline 10 & 0 & 0 & 0 & 0.44 & 0.45 \\
\hline 11 & 0 & 0 & 0 & 0.43 & 0.45 \\
\hline 12 & 0 & 0 & 0 & 0.44 & 0.45 \\
\hline 13 & 0 & 0 & 0 & 0.44 & 0.45 \\
\hline 14 & 0 & 0 & 0 & 0.43 & 0.45 \\
\hline 15 & 0 & 0 & -1.68 & 1.07 & 0.86 \\
\hline 16 & 0 & 0 & +1.68 & 0.48 & 0.56 \\
\hline 17 & 0 & -1.68 & 0 & 0.33 & 0.24 \\
\hline 18 & 0 & +1.68 & 0 & 0.44 & 0.35 \\
\hline 19 & -1.68 & 0 & 0 & 0.36 & 0.29 \\
\hline 20 & +1.68 & 0 & 0 & 0.41 & 0.31 \\
\hline
\end{tabular}

As can be seen from table 2, the best result is obtained for a temperature of $45^{\circ} \mathrm{C}$ and for the smallest size (Exp $\left.\mathrm{N}^{\circ} 15\right)$. The determination of optimum gave as that the relative minimum is obtained for a temperature of $44{ }^{\circ} \mathrm{C}$ and for the smallest size. The optimum therefore based only on table 2 is corresponding to $\operatorname{Exp} \mathrm{N}^{\circ} 15$ which gave the best mass extracted.

All the results obtained for the factorial design and composite design are resembled in table 3.

Table 3. Recapitulation of the results.

\begin{tabular}{|l|l|l|}
\hline & DF & CD \\
\hline Correlation coefficient & 0.82 & 0.82 \\
\hline Residue analysis & $\begin{array}{l}\text { Non } \\
\text { uniform }\end{array}$ & $\begin{array}{l}\text { Middle- } \\
\text { uniform }\end{array}$ \\
\hline Adjusted coefficient & 0.64 & 0.68 \\
\hline Regression analysis & Average & Good \\
\hline
\end{tabular}

\section{Conclusion}

The factorial design allowed us a better insight into the influencing factors. The presence of curvature led us to correct the model by proposing the model of second order. These preliminary results are interesting and we think further investigations on this plant.

\section{References}

1. C. Manach, A. Scalbert, C. Morand, C. Rémésy, L. Jiménez, American Journal of Clinical Nutrition 79 727 (2004)

2. J. Oszmianski, Przem. Spo. 394 (1995)

3. B. D._ynska, A. Stepniewska, R. Wołosiak, Acta Sci. Pol. 627 (2007)

4. R. Julkunen-Tiito, J. Agric. food. Chem. 33 (1985)

5. V.L. Singleton and J.A. Jr. Rossi, American Journal of Enology and Viticulture 16144 (1965) 